\title{
Sequential effects of signaled and unsignaled variations in reinforcement magnitude on fixed-interval performance
}

\author{
DONALD MELTZER and D. LYNN HOWERTON \\ Southern Ilinois University, Carbondale, Ilinois 62901
}

\begin{abstract}
Nine rats were reinforced for barpressing on a FI 3-min schedule. Every odd-numbered interval (i.e., the first, third, fifth, etc. interval in the session) ended with a two-pellet reinforcement. Even-numbered intervals ended with either a one- or a three-pellet reinforcement. During nondiscrimination sessions, a light was on during the even-numbered intervals while no light was on during the odd-numbered intervals. These were called nondiscrimination sessions because the subject could not predict the number of pellets it would receive at the end of the variable reinforcement interval. During discrimination sessions, light plus tone was presented in intervals which ended with one pellet, and light plus click was presented during intervals which ended with three pellets. The animals learned to discriminate between these auditory stimuli. It was shown that the subjects made more responses during the last half of an interval following a one-pellet reinforcement during discrimination sessions as compared to nondiscrimination sessions. These results indicate that behavioral contrast was produced by the discriminative stimuli.
\end{abstract}

A number of experiments have shown that the unpredictable omission of a reinforcement increases the subsequent response rate of subjects when free operant procedures are used (e.g., Jensen \& Fallon, 1973; Kello, 1972; Platt \& Senkowski, 1970; Scull, Davies, \& Amsel, 1970; Staddon, 1970a; Staddon \& Innis, 1969; Zaslav \& Porter, 1974; Zeiler, 1972; Zimmerman, 1971). Similar effects have been reported following reinforcement reduction by Meltzer and Howerton (1973) and Staddon (1970b). Most of these papers have referred to Amsel's $(1962,1967)$ frustration theory as a possible explanation of this effect but Staddon (1970a) and Kello (1972) have suggested an alternative hypothesis. They said that reinforcement had a temporary inhibition effect on responding when the experimental contingencies were such as to prevent the subject from earning a second reinforcement immediately after the first. Consequently, omitted reinforcements meant that there was no inhibition present and that the subjects would respond at a high rate. Staddon (1974) recently extended this hypothesis by saying that the subject's failure to inhibit responding after an omitted or reduced reinforcement was not primarily an emotional or motivational phenomenon but was instead a consequence of the fact that subjects could not remember nonreinforcement as well as they could remember reinforcement. He showed that if pigeons pecked at a key on which the stimulus was correlated with the event (i.e., reinforcement or nonreinforcement) that began the interval, the difference between response rates in the two types of interval disappeared.

However, all of the experiments described above were

The second author is now at Arkansas State University, Box 162, State University, Arkansas 72467. experiments in which the subject was either unable to predict whether or not reinforcement would be delivered at the end of the interval, or unable to predict the size of the reinforcement. Scull, Davies, \& Amsel (1970) examined the question of whether response rate following unpredictable omissions or reduction of reinforcement was different from rate following predictable omission or reduction. They showed that when rats were reinforced at the end of a 30-sec interval half of the time and not reinforced the other half of the time, response rates during a $30-s e c$ interval following nonreinforcement were higher than response rates during a 30-sec interval after reinforcement. This was true for subjects in a group in which discriminative stimuli signaled reinforcement or nonreinforcement as well as in a group in which no discriminative stimuli were used. Moreover, the difference between response rate after reinforcement and response rates after nonreinforcement was the same in the two groups. Amsel (1971) said that there was no reason to believe that response rate differences after reinforcement as compared to nonreinforcement were affected by the presence or absence of discriminative stimuli. The present study examined the different effects of large and small reinforcements on the subsequent behavior of the same subjects both when amount of reinforcement was signaled and unsignaled.

\section{METHOD}

\section{Subjects}

The subjects were nine hooded rats which had been bred in our laboratory. They were approximately 100 days old at the beginning of the experiment. Each animal was allowed free access to food for $1 \mathrm{~h}$ in its home cage immediately after an experimental session. Sessions were scheduled 5 days a week. Water was always available to an animal in its home cage. 


\section{Apparatus}

Each of the two identical chambers (Lehigh Valley Electronics No. 1316) had the following specifications. Interior dimensions were $21.0 \times 30.5 \times 18.0 \mathrm{~cm}$. A bar requiring a force of $18-20 \mathrm{~g}$ was located on the left side of the front wall, $3.5 \mathrm{~cm}$ above the grid floor. Food reinforcement consisted of either 1 , 2, or 3 45-mg Noyes pellets, delivered into a food hopper located in the middle of the front wall. If two or three pellets were to be delivered, the time between pellet presentations was no longer than $.5 \mathrm{sec}$. Two incandescent white lights, each emitting $37.1 \mathrm{fL}$ of illuminance, measured $.5 \mathrm{~cm}$ from the source, were located on either side of the front wall $9.0 \mathrm{~cm}$ above the floor. A Knight pure tone generator was used in presenting a $830-\mathrm{Hz}$ tone, $2.5 \mathrm{~dB}$ above background noise, through a speaker mounted just outside the chamber. An audible click of 8 pulses/second could also be presented through the same speaker by means of a Scientific Prototype click generator (No. 4041J).

White noise was present in the experimental room to mask extraneous sounds. Electromechanical programming and recording equipment was in an adjoining room.

\section{Procedure}

During the first three sessions, the subjects were conditioned to eat from the food hopper, and each barpress was reinforced with one $45-\mathrm{mg}$ Noyes pellet. For the remaining 53 sessions of the experiment, barpressing was reinforced on a FI 3-min schedule, and there were 17 3-min intervals in a session. Every odd-numbered interval (i.e., the first, third, fifth, etc., interval in the session) ended with a two pellet reinforcement. Four of the even-numbered intervals ended with a one-pellet reinforcement, and four of the even-numbered intervals ended with a three-pellet reinforcement. Thus, a two-pellet reinforcement was always preceded by either a one- or a three-pellet reinforcement except for the first interval of the session. The order of the one- and three-pellet reinforcements was changed every session. Each sequence was arranged so that there was an equal probability that an odd-numbered one-pellet interval would be followed in the next odd interval by either a one-pellet or a three-pellet interval. An odd-numbered three-pellet interval was equally likely to be followed in the next odd interval by either a one-pellet or a three-pellet interval. In discrimination sessions, light plus tone was present during intervals which ended with one pellet, and light plus eight clicks per second was present during intervals which ended with three pellets. In nondiscrimination sessions, light was present during intervals ending with either one or three pellets, but, since no auditory stimuli were present, there was no way for the subject to discriminate whether one or three pellets would be delivered at the end of the interval. During a two-pellet interval in both discrimination and nondiscrimination sessions, the light was off and there were no auditory stimuli.

Each interval was divided into three parts: the first $90 \mathrm{sec}$ the next $60 \mathrm{sec}$, and the final $30 \mathrm{sec}$. The intervals were divided into four different types as well: (1) intervals following a onepellet reinforcement, known as 1-2 intervals; (2) intervals following a three-pellet reinforcement which ended with a twopellet reinforcement which ended with a two-pellet reinforcement, known as 1-2 intervals; (2) intervals following a threepellet reinforcement which ended with a two-pellet reinforcement, known as 3-2 intervals; (3) $2-1$ intervals; and (4) $2-3$ intervals. All of the responses during the first $90 \mathrm{sec}$ of all the 11-2 intervals were entered on one counter. All the responses during the next $60 \mathrm{sec}$ of all the 1-2 intervals were entered on a second counter, and all of the responses during the final $30 \mathrm{sec}$ of all the 1-2 intervals were entered on a third counter. Responses during the 1-3, 2-1, and 2-3 intervals were tabulated in the same way. Each subject's data from the last 10 nondiscrimination sessions and from the last 10 discrimination sessions were first converted to mean number of responses

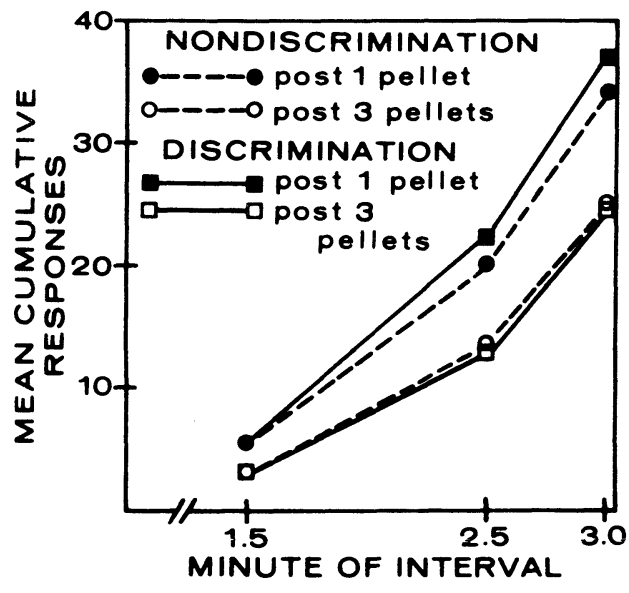

Figure 1. Mean cumulative responses in intervals ending with a two-pellet reinforcement are shown as a function of whether the preceding interval ended with a one-pellet or a three-pellet reinforcement, and also as a function of whether or not a discriminative stimulus was present during the preceding interval.

during each time bin in each kind of interval and then were examined in an analysis of variance.

\section{RESULTS}

The first analysis was performed on the constant reinforcement intervals only. This was an attempt to determine the effects of the preceding amount of reinforcement, and the effect of the presence or absence of a discriminative stimulus in the variable reinforcement interval, on responding during the constant reinforcement interval. The subjects made a mean of 35.9 responses in an interval following a one-pellet reinforcement and 25.3 responses in an interval following a threepellet reinforcement. This difference was significant $(\mathrm{F}=34.59, \mathrm{df}=1 / 8, \mathrm{p}<.001)$. They made a mean of 4.3 responses during the first $90 \mathrm{sec}$, a mean of 13.1 responses during the next $60 \mathrm{sec}$, and a mean of 13.2 responses during the last $30 \mathrm{sec}$ of the interval. Finally, there was a significant interaction between segments of the interval, amount of preceding reinforcement, and the presence or absence of a discriminative stimulus during variable reinforcement intervals $(F=5.21, \mathrm{df}=2 / 16$, $\mathrm{p}<.025$ ) which is shown in Figure 1. This interaction simply means that the difference between responses in different segments of the interval following one and three pellets was greater when a discriminative stimulus had signaled the amount of reinforcement than when no discriminative stimulus was present. Figure 1 shows that neither the amount of the preceding reinforcement nor the predictability of the reinforcement in the preceding interval affected the number of responses subjects made in the first half of the current interval. If a preceding one-pellet reinforcement had been signaled, the rats made a mean of 5.4 responses during the first $90 \mathrm{sec}$ of the current interval; if it had not been signaled, they also made a mean of 5.4 responses. If a preceding three- 


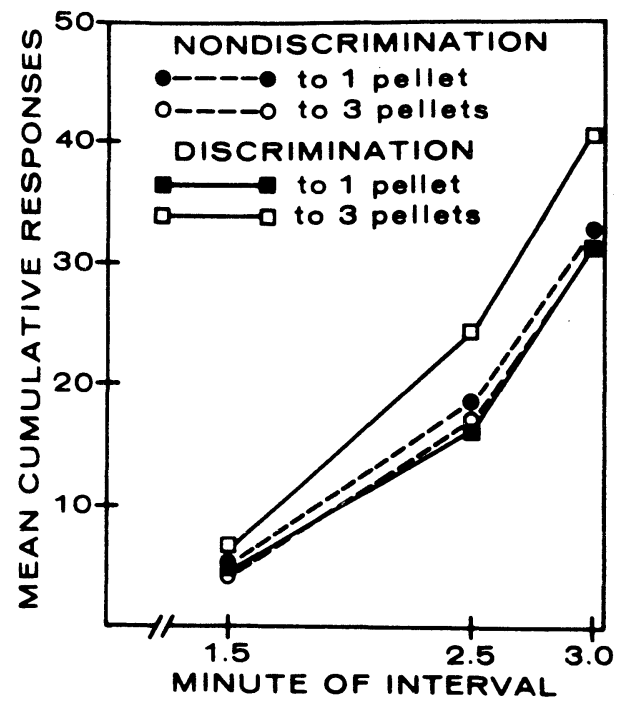

Figure 2. Mean cumulative responses in intervals ending with either a one- or a three-pellet reinforcement are shown as a function of whether or not a discriminative stimulus was present during the interval.

pellet reinforcement had been signaled, they made a mean of 3.0 responses during the first $90 \mathrm{sec}$ of the current interval; if it had not been signaled, they made a mean of 3.4 responses.

During the last $90 \mathrm{sec}$ of the interval, the subjects made almost the same number of responses following a signaled as compared to an unsignaled three-pellet reinforcement; a mean of 22.0 responses following a signaled reinforcement and a mean of 22.3 responses following an unsignaled three-pellet reinforcement. But they made more responses following a signaled as compared to an unsignaled one-pellet reinforcement-a mean of 32.0 responses following a signaled one-pellet reinforcement and a mean of 28.9 responses following an unsignaled one-pellet reinforcement.

In order to conclude that the differences actually were a consequence of whether or not the subjects could predict the amount of reinforcement, it was necessary to show that discriminative stimuli really did have control over behavior. Therefore, the data from the variable reinforcement intervals were also analyzed. Figure 2 shows that the subjects made a mean of 40.6 responses during intervals which ended with a threepellet reinforcement in sessions in which a discriminative stimulus was present. They made a mean of only 30.6 responses in the same sessions during intervals which ended with a one-pellet reinforcement. There was almost no difference in the number of responses they made during one- and three-pellet intervals in nondiscrimination sessions, a mean of 33.3 and 31.5 responses, respectively. This interaction between the amount of reinforcement at the end of the interval and the presence or absence of discriminative stimuli was significant $(F=7.73, \mathrm{df}=1 / 8, \mathrm{p}<.025)$, and stimulus control was seen to be effective. There was also a significant effect of segment of the interval $(F=18.98, d f=2 / 16$, $\mathrm{p}<.01$ ). During all variable reinforcement intervals, subjects made a mean of 5.0 responses during the first $90 \mathrm{sec}, 14.1$ responses during the next $60 \mathrm{sec}$, and 14.8 responses during the last $30 \mathrm{sec}$. No other main effects or interactions were significant.

The effect of the discriminative stimulus on responses during the following interval might be simply explained if the subjects had responded at a lower rate during the intervals which ended with a one-pellet reinforcement in discrimination sessions as compared to nondiscrimination sessions. However, there was no difference between the number of responses subjects made during these intervals in the two types of sessions. In addition to that, the number of responses subjects made during intervals following a three-pellet reinforcement was the same in discrimination and nondiscrimination sessions even though they made many more responses during the interval which ended with a three-pellet reinforcement in discrimination sessions. When these data are considered, there does not seem to be any reason to assume that differences in the absolute number of responses subjects made during the variable reinforcement intervals in discrimination as opposed to nondiscrimination sessions, were responsible for the differences observed during the constant reinforcement intervals in the two types of sessions.

\section{DISCUSSION}

The most important aspect of these data was the demonstration that subjects made more responses after a small reinforcement when it was predictable as opposed to unpredictable. This is not consistent with the results reported by Scull et al. (1970), but there were many procedural differences between their study and this one. They used reinforcement omission rather than reinforcement reduction; they used a betweensubject design rather than a within-subject design; and the intervals in which they sought contrast effects were intervals which could end with unpredictable omission of reinforcement rather than constant reinforcement. Any of these differences may be responsible for the discrepant results of the two studies.

When Amsel (1971) discussed the Scull et al. (1970) experiment, he said that their results could be used to explain the phenomenon of behavioral contrast which was described by Reynolds (1961). Reynolds first conditioned pigeons to peck at a key when it was transilluminated by either of two colored stimuli. Responses were intermittently reinforced regardless of which stimulus was present. During the second part of the experiment, responses were still reinforced on the sam schedule when one of the two colors ( $\mathrm{S}+$ ) was on the key, but responses were extinguished when the other color (S-) was presented. Response rate was much higher during the presentation of the $S+$ in the second part of the experiment than it had been when the same stimulus was displayed on the key during the first part of the experiment. This was true even though the schedule of reinforcement during S+ displays was the same in both parts of the experiment. The increases in response rate was called behavioral contrast. Recent reviews by Terrace (1972) and Freeman (1971a) showed that these findings have been confirmed repeatedly in experiments in which pigeons learned a discrimination between visual stimuli presented on the response key. However, 
it is not as certain that rats will show behavioral contrast under similar conditions. Freeman (1971b) found no evidence of behavioral contrast in the rat, and Pear and Wilkie (1971) found found evidence of contrast in one phase of their experiment but contradictory results in another phase. One the other hand, Wilkie (1972) and Gutman, Sutterer, and Brush (1975) did show clear contrast effects in the rat. One variable that may be implicated in the different results is the amount of prediscrimination conditioning. Apparently a long period of such conditioning is necessary if contrast effects are to be shown in the rat when the traditional operant multiple schedule procedure is used.

It is not clear that variations in the amount of reinforcement at the end of a fixed interval are analagous to the procedures which have been previously used to show behavioral contrast. Nevertheless, the behavioral contrast literature would seem to imply that the subjects in this experiment should respond at a higher rate after a predictable one-pellet reinforcement than after an unpredictable one-pellet reinforcement, and that is what they did. Our subjects did not show any negative contrastthat is, lower rates after predictable as compared to an unpredictable three-pellet reinforcement. Therefore, the similarity of the processes which produced these results and those which produce the typical contrast phenomenon is questionable.

Finally, it must be pointed out that the magnitude of the limited contrast effects which we did observe was quite small compared with the effects of preceding amount of reinforcement on current responses.

\section{REFERENCES}

Amsel, A. Frustrative nonreward in partial reinforcement and discrimination learning: Some recent history and a theoretical extension. Psychological Review, 1962, 69, 306-328.

AMSEL, A. Partial reinforcement effects on vigor and persistence. In: K. W. Spence \& J. T. Spence (Eds.), The psychology of learning and motivation. New York: Academic Press, 1967.

AMSEL, A. Positive induction, behavioral contrast, and generalization of inhibition in discrimination learning. In: H. H. Kendler \& J. T. Spence (Eds.), Essays in Neobehaviorism. New York: Appleton-Century-Crofts, 1971.

FreEman, B. J. Behavioral contrast: Reinforcement frequency or response suppression? Psychological Bulletin, 1971, 75, 347-356. (a)

Freeman, B. J. The role of response-independent reinforcement in producing behavioral contrast effects in the rat. Learning and Motivation, 1971, 2, 138-147. (b)

Gutman, A., Sutterer, J. R., \& Brush, F. R. Positive and negative behavioral contrast in the rat. Journal of the Experimental Analysis of Behavior, 1975, 23, 377-383.
JENSEN, C., \& FAllon, D. Behavioral aftereffects of reinforcement and its omission as a function of reinforcement magnitude. Journal of the Experimental Analysis of Behavior, 1973, 19. 459-468.

KeLLO. J. E. The reinforcement-omission effect on fixed-interval schedules: Frustration or inhibition? Learning and Motivation, 1972, 3, 138-147.

Meltzer, D., \& Howerton, D. L. Sequential effects of reinforcement magnitude on fixed-interval performance. Journal of Comparative and Physiological Psychology, 1973, 85, 361-366.

Pear, J. J., \& Wilkie, D. M. Contrast and induction in rats on multiple schedules. Journal of the Experimental Analysis of Behavior, 1971, 15, 289-296.

Platt, J. R., \& Senkowski, P. C. Effects of discretetrials reinforcement frequency and change in reinforcement frequency on preceding and subsequent fixed-ratio performance. Journal of Experimental Psychology, 1970, 85, 95-104.

Reynolds, G. S. Attention in the pigeon. Journal of the Experimental Analysis of Behavior, 1961, 4, 203-208.

Scull, J., Davies, K., \& AmSEl, A. Behavioral contrast and frustration effect in multiple and mixed fixed-interval schedules in the rat. Journal of Comparative and Physiological Psychology, 1970, 71, 478-483.

Staddon, J. E. R. Temporal effects of reinforcement: A negative "frustration" effect. Learning and Motivation, 1970. 1. 227-247. (a)

Staddon, J. E. R. Effects of reinforcement duration in fixed interval responding. Journal of the Experimental Analysis of Behavior, 1970, 13, 9-11. (b)

Staddon, J. E. R. Temporal control, attention and memory. Psychological Review, 1974, 81, 375-391.

Staddon, J. E. R., \& Innis, N. K. Reinforcement omission on fixed-interval schedules. Journal of the Experimental Analysis of Behavior, 1969, 12, 689-700.

Terrace, H. S. By-products of discrimination learning. In G. H. Bower (Ed.), The psychology of learning and motivation. New York: Academic Press, 1972.

WILKIE, D. M. Variable time reinforcement in multiple and concurrent schedules. Journal of the Experimental Analysis of Behavior, 1972, 17, 59-66.

Zaslav, M. R., \& Porter, J. J. The effects of reinforcement frequency on performance in a multiple fixed-ratio schedule. Animal Learning and Behavior, 1974, 2, 54-58.

ZEILER, M. D. Fixed-interval behavior: Effects of percentage reinforcement. Journal of the Experimental Analysis of Behavior, 1972, 17, 177-189.

Zimmerman, D. W. Rate changes after unscheduled omission and presentation of reinforcement. Journal of the Experimental Analysis of Behavior, 1971, 15, 261-270.

(Received for publication July 10, 1975.) 